University of Nebraska - Lincoln

DigitalCommons@University of Nebraska - Lincoln

USDA Wildlife Services - Staff Publications

U.S. Department of Agriculture: Animal and Plant Health Inspection Service

2018

Seroconversion of Raccoons Following Two Oral Rabies

Vaccination Baiting Strategies

\author{
Are R. Berentsen \\ USDA/APHIS/WS/National Wildlife Research Center, are.r.berentsen@aphis.usda.gov \\ Erin M. Patrick \\ USDA/APHIS/Wildlife Services \\ Chad Blass \\ USDA/APHIS/WS/National Wildlife Research Center \\ Keith Wehner \\ USDA/APHIS/Wildlife Services, keith.p.wehner@aphis.usda.gov \\ Brett Dunlap \\ USDA/APHIS/Wildlife Services
}

See next page for additional authors

Follow this and additional works at: https://digitalcommons.unl.edu/icwdm_usdanwrc

Part of the Life Sciences Commons

Berentsen, Are R.; Patrick, Erin M.; Blass, Chad; Wehner, Keith; Dunlap, Brett; Hicks, Bradley; Hale, Robert; Chipman, Richard B.; and VerCauteren, Kurt C., "Seroconversion of Raccoons Following Two Oral Rabies Vaccination Baiting Strategies" (2018). USDA Wildlife Services - Staff Publications. 2053.

https://digitalcommons.unl.edu/icwdm_usdanwrc/2053

This Article is brought to you for free and open access by the U.S. Department of Agriculture: Animal and Plant Health Inspection Service at DigitalCommons@University of Nebraska - Lincoln. It has been accepted for inclusion in USDA Wildlife Services - Staff Publications by an authorized administrator of DigitalCommons@University of Nebraska - Lincoln. 


\section{Authors}

Are R. Berentsen, Erin M. Patrick, Chad Blass, Keith Wehner, Brett Dunlap, Bradley Hicks, Robert Hale, Richard B. Chipman, and Kurt C. VerCauteren 


\title{
Seroconversion of Raccoons Following Two Oral Rabies Vaccination Baiting Strategies
}

\author{
ARE R. BERENTSEN, ${ }^{1}$ USDA/APHIS/WS/National Wildife Research Center, 4101 LaPorte Ave., Ft. Collins, CO 80521, USA \\ ERIN M. PATRICK, USDA/APHIS/Wildlife Services, 4708 Western Ave., Suite A, Knoxville, TN 37921, USA \\ CHAD BLASS, USDA/APHIS/WS/National Wildlife Research Center, 4101 LaPorte Ave., Ft. Collins, CO 80521, USA \\ KEITH WEHNER, USDA/APHIS/Wildlife Services, 537 Myatt Dr., Madison, TN 37115, USA \\ BRETT DUNLAP, USDA/APHIS/Wildlife Services, 537 Myatt Dr., Madison, TN 37115, USA \\ BRADLEY HICKS, USDA/APHIS/WS/National Rabies Management Program, 1100 W. 49th St., Austin, TX 78756, USA \\ ROBERT HALE, USDA/APHIS/WS/National Rabies Management Program, 4469 Professional Pkwy, Groveport, OH 43125, USA \\ RICHARD B. CHIPMAN, USDA/APHIS/WS/National Rabies Management Program, 59 Chenell Dr., Suite 2, Concord, NH, USA \\ KURT C. VERCAUTEREN, USDA/APHIS/WS/National Wildife Research Center, 4101 LaPorte Ave., Ft. Collins, CO 80521, USA
}

\begin{abstract}
Seroprevalence of rabies virus neutralizing antibodies (rVNA) in raccoons (Procyon lotor) following oral rabies vaccination (ORV) with RABORAL V-RG ${ }^{\mathbb{B}}$ in the United States has annually averaged $30 \%$ since 1997 , a level that is unlikely to successfully interrupt rabies transmission in raccoon populations. A longitudinal ORV zone is maintained in the eastern United States with raccoon variant rabies established east of the zone but absent to the west. However, questions remain regarding the effect of the bait application strategy towards achieving optimal population immunity. We estimated the number of ORV baits $/ \mathrm{km}^{2}$ of raccoon home range and calculated rVNA seroprevalence following 2 ORV baiting strategies: cluster baiting ( $\leq 10$ baits dropped at a time) via helicopter and hand distribution of individual baits at regular intervals along roads and trails in suburban Chattanooga, Tennessee, USA, during fall 2013 and 2014. We applied baits at 75 baits $/ \mathrm{km}^{2}$ under both strategies. We established $61-\mathrm{km}^{2}$ cells in each treatment area, and fitted $\leq 2$ raccoons with global positioning system collars in each cell. We trapped and sampled $\leq 25$ raccoons in each study cell pre- and post-ORV application for rVNA analysis. Overall raccoon home range and core area estimates were $80.7 \mathrm{ha}$ and $17.5 \mathrm{ha}$, respectively $(n=36)$. Average bait application for home ranges ( $n=32$ home ranges that received bait) was 80.9 baits $/ \mathrm{km}^{2}$ for helicopter baiting and $63.6 \mathrm{baits} / \mathrm{km}^{2}$ for hand baiting sites. Average bait application for core areas was 104.7 baits $/ \mathrm{km}^{2}$ for helicopter baiting and 69.2 baits/ $\mathrm{km}^{2}$ for hand baiting sites. All home ranges were baited in both treatment areas, whereas 10/18 and 13/14 core areas were baited in the helicopter and hand distribution sites, respectively. Overall, helicopter cluster ORV delivered more baits $/ \mathrm{km}^{2}$ of raccoon home range than hand distribution but was less effective in reaching core areas. Seroprevalence did not change as a function of baiting strategy (helicopter vs. hand baiting). The average overall increase in seroprevalence following ORV application was 8.9\%. Evaluation of additional strategies are needed because both methods failed to achieve herd immunity necessary to disrupt rabies transmission in raccoons. (C) 2017 The Wildlife Society.
\end{abstract}

KEY WORDS oral rabies vaccination, Procyon lotor, rabies, raccoon, suburban, Tennessee.

In the late 1970s, raccoon rabies virus variant (RRV) was found in a raccoon (Procyon lotor) that had been translocated to West Virginia, USA and since the mid 1980s, RRV has spread throughout the eastern United States, into regions of Ohio and Tennessee (Rupprecht and Smith 1994, Krebs et al. 2005). Since 1997, the United States Department of Agriculture, Animal and Plant Health Inspection Service, Wildlife Services has conducted cooperative oral rabies

Received: 20 April 2017; Accepted: 14 August 2017

${ }^{1}$ E-mail: are.r.berentsen@aphis.usda.gov vaccination (ORV) programs throughout the eastern United States to prevent the spread of RRV (Slate et al 2005). However, questions remain regarding the effectiveness of current ORV baiting strategies in vaccinating a sufficient proportion of the raccoon population to eliminate RRV transmission.

The only oral rabies vaccine currently licensed for use in wildlife in the United States is RABORAL V-RG (Merial Inc., Athens, GA, USA). Although vaccination thresholds have not been established for eliminating rabies in freeranging raccoons, seroconversion rates in raccoons following ORV application using RABORAL V-RG were approximately 30\% from 1997 to 2007 (Slate et al. 2009), well below 
the threshold of $60-90 \%$ generally recommended to interrupt rabies virus transmission (Thulke and Eisinger 2008, Rees et al. 2013, Reynolds et al. 2015). In urban and suburban ecosystems, Robbins et al. (1998) suggested vaccination rates of $63 \%$ may be sufficient to halt the spread of raccoon rabies via ORV distribution and Rosatte et al. (2009) suggested up to $79 \%$ vaccination was required during trap-vaccinate-release programs. Currently it is unknown whether the observed seroconversion rate is due to the vaccine performance in field situations, lack of access by target species to the vaccine-bait, non-target bait competition (but see Olson et al. 2000 for a discussion of ORV consumption by Virginia opossums [Didelphis virginianus], gray foxes [Urocyon conereoargenteus] and feral cats $[$ Felis catus]), overall unattractiveness of the bait itself, or incomplete bait ingestion (i.e., consuming only the outer coating while leaving the vaccine sachet intact).

Operationally in the United States, ORV baits are distributed at a bait density of 75 baits $/ \mathrm{km}^{2}$, or alternatively $150 / \mathrm{km}^{2}$ under special circumstances such as in response to an outbreak, along sensitive border areas, and in habitats with demonstrated higher raccoon densities (e.g., some suburban areas). Bait application is performed by distributing individual baits at regular intervals along transects via fixed-wing aircraft, helicopter, or by hand along established roads, trails, and other walkways. Research suggests the current baiting strategies are similar with respect to seroconversion rates. Boulanger et al. (2008) reported no difference in antibody response in raccoons among ORV distribution by helicopter, hand distribution, or bait stations (which provide a continuous and clustered source of ORV baits) in a suburban environment. Sattler et al. (2009) evaluated seroconversion among 3 different application rates $\left(75,150\right.$, and 300 baits $\left./ \mathrm{km}^{2}\right)$ using helicopter and hand-vehicle bait distribution but did not differentiate between methods ( $\sim 84 \%$ of baits were aerially distributed), only application rates. Blackwell et al. (2004) suggested that when distributed at a density of 75 baits $/ \mathrm{km}^{2}$, an average of 3.3 baits/raccoon was consumed, but these results were not confirmed relative to raccoon density and remain largely speculative. Further, Beasley et al. (2015) suggested the use of resource selection data to target specific land cover types did not increase ORV uptake in regions evaluated.

The aforementioned studies provide insight into ORV bait uptake under current baiting strategies in a variety of land cover types and, in some cases, application rates. However, they do not consider uptake under a clustered bait distribution strategy where multiple baits are aerially distributed at a lower distribution frequency than single baits but at the same overall density. Clustered resources may cause some species to alter their space use to include that resource and possibly result in increased resource consumption. For example, Wehtje and Gompper (2011) reported increased spatial overlap among female raccoons in response to experimentally placed clumped food resources. Campbell and Long (2007) reported feral pigs (Sus scrofa) removed baits in a clustered arrangement at a higher rate than expected. In
New Zealand aggregated distribution of compound 1080 (sodium fluoroacetate) was reported to be as effective as broadcast applications in controlling brushtail possum (Trichosurus vulpecula) populations (Nugent et al. 2012). In Ohio, ORV baits distributed in clusters of 8 baits every 13 seconds resulted in higher seroconversion rates, particularly among juvenile raccoons, than a single bait distributed every 2 seconds (U.S. Department of Agriculture [USDA] unpublished data). Comparing seroprevalence and bait availability following aerial cluster baiting versus hand broadcast baiting strategies may provide insight into which strategy may be more effective in achieving the desired population immunity in target wildlife in a suburban environment.

Our objectives were to evaluate rVNA seroprevalence in raccoons pre- and post-ORV distribution via cluster baiting from helicopter and hand distribution of single baits and evaluate ORV bait availability in raccoon home ranges under each baiting strategy. We hypothesized aerial cluster baiting would provide more complete bait coverage and, thus, higher seroconversion rates than hand distribution.

\section{STUDY AREA}

We conducted this study in Chattanooga, Hamilton County, Tennessee during summer and fall 2013 and 2014. We established a northern and southern study site. Both sites have a history of annual ORV application with an average seroprevalence of $33.3 \%$ following application at 75 baits $/ \mathrm{km}^{2}$ between 2008 and 2012 (USDA National Rabies Management Program [NRMP], unpublished data). Study sites were separated by the Chickamauga River and Chickamauga Lake to reduce potential raccoon movement between study sites (Fig. 1). Each site consisted of a heterogeneous mixture of low to moderate intensity development, interspersed with deciduous and evergreen forest. Chattanooga has a temperate climate with average temperatures ranging from $-0.5^{\circ} \mathrm{C}$ in January to $32.2^{\circ} \mathrm{C}$ in July. Average annual rainfall is $1,332 \mathrm{~mm}$, which falls throughout the year. In addition to raccoons, local fauna includes opossums, striped skunks (Mephitis mephitis), gray fox, coyote (Canis latrans), beaver (Castor canadensis), muskrat (Ondatra zibethicus), white-tailed deer (Odocoileus virginianus), and various small mammals. The northern study site consisted primarily of deciduous forest (33.4\%), large areas of open water (22.4\%), and developed open space (9.3\%). The southern study site consisted primarily of developed open space (36.1\%), low intensity development (18\%), and deciduous forest (12.6\%; USDA 2011).

\section{METHODS}

\section{Capture and Handling}

We live captured raccoons up to 12 weeks prior to and 5-6 weeks following ORV bait application using cage traps (Tomahawk Live Trap, Hazelhurst, WI, USA) baited with marshmallows and fruit extract. We immobilized each captured raccoon via intramuscular injection of 5:1 ketamine: 


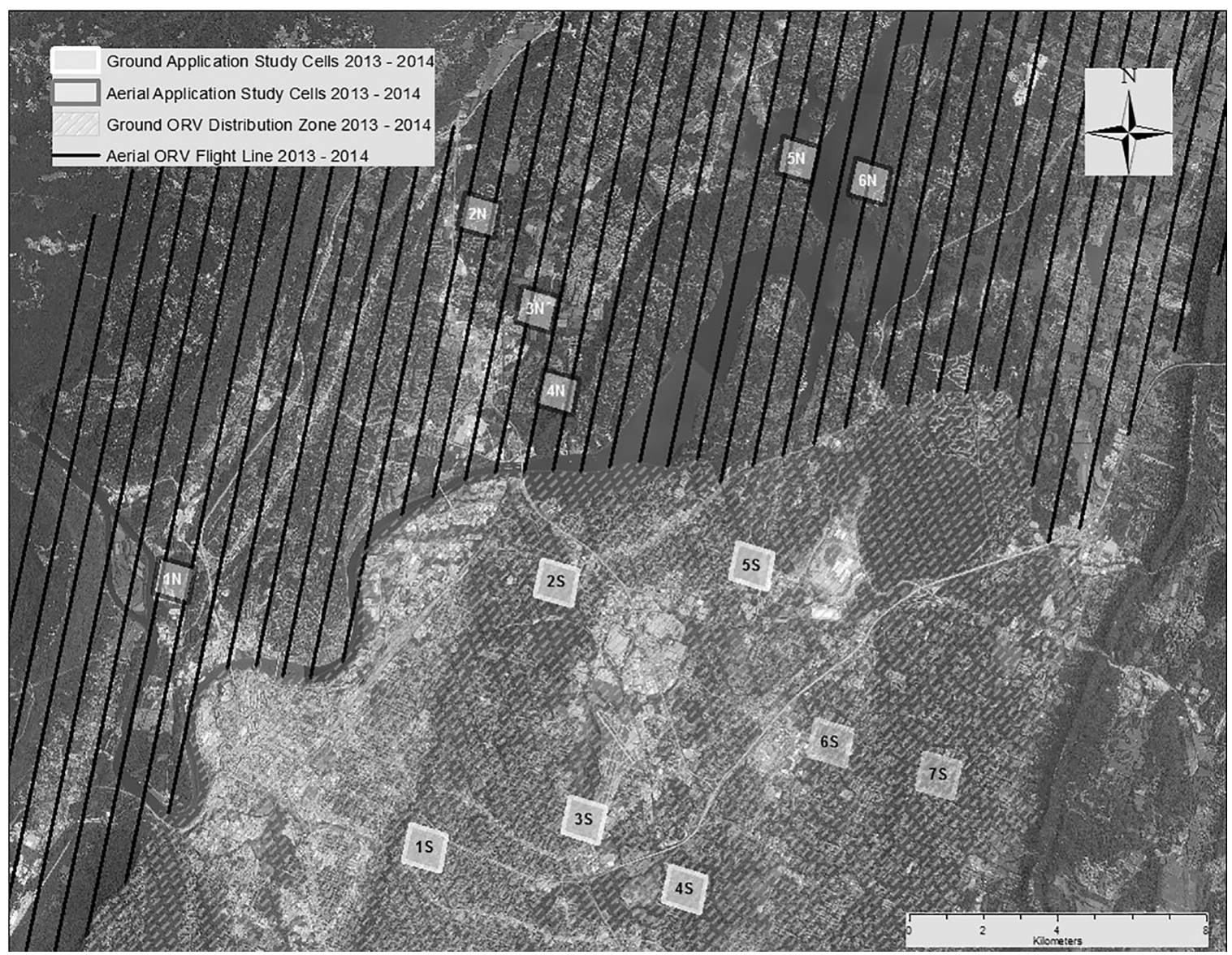

Figure 1. Flight lines and locations of oral rabies vaccination (ORV) aerial and hand broadcast study cells, Chattanooga, Tennessee, USA, $2013-2014$.

xylazine (Kreeger and Arnemo 2007), applied uniquely labeled metal ear tags, and collected up to $3.0 \mathrm{ml}$ of whole blood from each raccoon via venipuncture of the jugular vein. We centrifuged blood samples, transferred serum to cryovials, and froze them. Upon initial capture, we fitted $\leq 2$ raccoons $(1 \mathrm{M}, 1 \mathrm{~F})$ in each cell with a radio-collar equipped with a global positioning system (GPS; Telonics, model TGW-4200-2, Mesa, AZ, USA and Telemetry Solutions, model Quantum 4000E, Concord, CA, USA). We programmed the collars to record a GPS location every 30-60 minutes for approximately 3 months, starting approximately 4 weeks prior to planned ORV bait application. We deployed store-on-board collars requiring collar retrieval for data collection in 2013 and collars with remote download capability in 2014. All capture and handling of animals was approved by the National Wildlife Research Center's Institutional Animal Care and Use Committee under research protocol QA-2178.

\section{Bait Application}

We applied baits aerially and by hand distribution at a rate of 75 baits $/ \mathrm{km}^{2}$ during annual operational ORV. We baited the northern study site with coated sachet baits by helicopter and hand-baited the southern site with fishmeal polymer baits while on foot or from vehicles. In each study site, we established $61-\mathrm{km}^{2}$ cells for raccoon serologic sampling and radio-collaring (Fig. 1). We moved 1 hand-baited study cell approximately $1.5 \mathrm{~km}$ southeast between 2013 and 2014 because of heavy construction.

We conducted aerial application by helicopter flying along transects spaced $750 \mathrm{~m}$ apart (Fig. 1) and depositing 1 bait approximately every $18 \mathrm{~m}$, until we encountered study cells. When flying over study cells, we suspended the normal distribution method and applied baits in clusters of 10 , with $178 \mathrm{~m}$ between clusters. In addition, we baited a 750-m (1 flight transect) buffer zone surrounding each $1-\mathrm{km}^{2}$ study cell to ensure each cell was adequately baited. We distributed baits by hand approximately every $25 \mathrm{~m}$ into raccoon habitat while driving along roads or walking established walking paths. During aerial broadcast over the individual study cells, we predetermined the location of each bait cluster and entered coordinates into the aircraft's GPS. During hand distribution, we recorded in a handheld GPS the location from which we threw the bait from the vehicle. Because we conducted bait application during a large-scale operational ORV distribution program, we recorded the location of bait clusters only when applying bait over the individual study cells, with a 750-m buffer surrounding each cell to account for potential raccoon movements outside the study cell borders.

We entered bait locations into ArcGIS (version 10.1; ESRI, Redlands, CA, USA). To account for bait separation during aerial application of bait clusters, we generated a $25-\mathrm{m}$ buffer around each cluster location in ArcGIS. We based the 
25-m distance on the mean distance from the bait drop location (recorded by the bait applicator in the helicopter) to the actual bait locations on the ground during a mock bait application performed under operational conditions (i.e., flight speed and altitude) prior to field operations. Buffer zones that intersected the perimeter of a home range or core area had 5 baits (50\%) assigned as inside the home range or core area.

\section{Data Analysis}

We shipped frozen serum samples to the Centers for Disease Control and Prevention (Atlanta, GA) for rabies virus neutralizing antibody (rVNA) analysis via rapid fluorescent focus inhibition test (RFFIT; Smith et al. 1996). We considered raccoons with RVNA titers $\geq 0.05 \mathrm{IU} / \mathrm{mL}$ seropositive. We calculated seroprevalence for each cell by dividing the number of seropositive animals by the total captured in that cell. We determined overall seroprevalence by calculating the mean seroprevalence for cells in each study area, pre- and post-vaccination. We used a generalized linear mixed model (function LMER in package LME4, program $\mathrm{R}$; Bates et al. 2015) to compare the difference between seropositive proportions pre- and post-ORV application, with study cells as random effects nested within each treatment area and bait strategy and year as fixed effects (Zuur et al. 2009). To account for unequal sample size, we weighted the cell values based on the number of animals sampled in each cell. We ranked models using Akaike's Information Criterion corrected for small sample sizes $\left(\mathrm{AIC}_{i}\right.$; Burnham and Anderson 2002) and considered models within $2 \Delta \mathrm{AIC}_{c}$ from the top model as competitive.

We evaluated GPS relocations of each collared raccoon for accuracy by visual inspection and dilution of precision of each relocation (Berentsen et al., 2014), and removed all inaccurate relocations from further analysis. We used the adehabitat statistical package in program $\mathrm{R}$ ( $\mathrm{R}$ Foundation for Statistical Computing, Vienna, Austria) to calculate utilization distributions (UDs) for each collared raccoon and determine the home range size at the 50\% (core) and 95\% (overall) contours and to estimate the number of baits that were dropped within the core and overall home ranges. We used the biased random bridge movement-based kernel density estimator (MKDE; Benhamou 2011) to calculate the UDs and extract the areas of the core and overall home range contours. Using the MKDE for our data allowed us to use all accurate GPS relocations because the MKDE accounts for serial correlation of consecutive relocations, periods of inactivity, and locational error associated with GPS relocations (Cornélis et al. 2011). We log-transformed mean core and overall home range sizes and mean baits $/ \mathrm{km}^{2}$ of home range and core area and compared means using the GLM procedure in SAS (SAS Institute, Cary, NC, USA). We considered results statistically significant when $P<0.05$.

\section{RESULTS}

We collected sera from 535 raccoons prior to vaccination during 2013-2014, 80 of which were seropositive. Following ORV application, we sampled 579 raccoons, 139 of which were seropositive. The overall average increase in seroprevalence following ORV application was 8.9\% $( \pm 11 \%$ [SE]; Table 1). Seroprevalence did not change as a function of baiting strategy or year (Table 2). Year showed a weak negative effect $(\beta=-0.05 \pm 0.04[\mathrm{SE}])$.

We fitted 43 raccoons with GPS collars (18 store-on-board in 2013, 25 remote-download in 2014). We did not recover 3 store-on-board collars and recovered 1 with insufficient data following mortality. One remote-download collar malfunctioned and we lost contact with 2 additional collars for unknown reasons a few weeks after deployment. We retrieved sufficient data to calculate home range estimates from 36 collars: 14 (10 M, 4F) in 2013 and 22 (11 M, 11 F) in 2014.

Mean overall home range was $80.7 \pm 1.07$ ha (range $=$ 15.2-323.2 ha, 95\% CI $=59.1-102.4)$ and mean core area was $17.5 \pm 2.4$ ha (range $=3.1-56.0$ ha, 95\% CI $=12.6-22.4$ ). Mean overall home range was $109.5 \pm 14.6$ ha (range $=$ 34.6-323.2 ha, 95\% CI $=79.1-140.0)$ for males and $40.3 \pm 7.5$ ha $($ range $=15.2-131.1$ ha, $95 \% \mathrm{CI}=24.3-56.4$ ) for females. Mean core area estimate was $24.4 \pm 2.4$ ha (range $=5.0-56.0 \mathrm{ha}, 95 \% \mathrm{CI}=17.7-31.2$ ) for males and $7.8 \pm 1.3$ ha (range $=3.1-23.1$ ha, $95 \% \mathrm{CI}=4.9-10.7$ ) for females. Males had larger overall home range estimates $(F=28.16, P<0.001)$ and core areas $(F=30.66, P<0.001)$ than females. There was no difference in overall home range $(F=0.02, \quad P=0.88)$ or core area estimates $(F=0.33$, $P=0.57)$ by year. Overall home range size $(F=3.31$, $P=0.08)$ and core areas $(F=1.46, P=0.23)$ did not differ between the aerial broadcast and hand baiting zones.

Four raccoons moved outside the cells or buffer areas in which we recorded bait application. We calculated baits $/ \mathrm{km}^{2}$ of home range and core area for 32 raccoon home ranges: 18 by aerial application and 14 by hand distribution. Of 18 home ranges baited by helicopter, 10/18 core areas received baits, whereas 13/14 core areas baited by hand distribution received baits. Average application was 80.9 \pm 8.6 (range $=49.9-196.7$, $95 \% \mathrm{CI}=62.7-99.1$ ) and $63.6 \pm 5.7$ (range $=25.6-97.2$, $95 \% \mathrm{CI}=51.2-76.0)$ baits $/ \mathrm{km}^{2}$ of home range for aerial and hand baiting sites, respectively. Average application for core areas that received baits was $104.7 \pm 28.7 \quad$ (range $=15.0-341.5,95 \% \quad \mathrm{CI}=39.7-169.7)$ and $69.2 \pm 12.5$ (range $=8.6-138.9,95 \% \mathrm{CI}=41.9-96.4)$ baits $/ \mathrm{km}^{2}$ of core area for aerial $(n=10)$ and hand baiting sites $(n=13)$, respectively. Baits $/ \mathrm{km}^{2}$ did not differ between aerial and hand distribution for overall home ranges $(F=3.12$, $P=0.08)$ or core areas $(F=1.12, P=0.30)$.

\section{DISCUSSION}

Seroprevalence between helicopter and hand baiting suggests that both are similar in delivering ORV baits to raccoons. Although not statistically significant, aerial cluster broadcast delivered more baits $/ \mathrm{km}^{2}$ of raccoon home range than hand distribution but was less efficient in reaching core areas. However, core areas represent a relatively small proportion of a raccoon's home range and the $178-\mathrm{m}$ interval between bait clusters along flight transects may have resulted in some core areas being missed. 
Table 1. Total captures and number of seropositive raccoons pre- and post-oral rabies vaccination (ORV) application, Chattanooga, Tennessee, USA, 2013-2014.

\begin{tabular}{|c|c|c|c|c|}
\hline & Pre-ORV captures & No. seropositive $(\% ; \mathrm{SE})^{\mathrm{a}}$ & Post-ORV captures & No. seropositive $(\%, \mathrm{SE})^{\mathrm{a}}$ \\
\hline \multicolumn{5}{|l|}{2013} \\
\hline Helicopter & 132 & $18(13.0 ; 2.4)$ & 152 & $38(25.7 ; 3.1)$ \\
\hline Hand baiting & 118 & 21 (17.4; 4.4) & 129 & $38(28.5 ; 6.3)$ \\
\hline Total & 250 & $39(15.2 ; 2.5)$ & 281 & $76(27.1 ; 3.4)$ \\
\hline \multicolumn{5}{|l|}{2014} \\
\hline Helicopter & 159 & $25(17.0 ; 3.7)$ & 168 & $36(21.9 ; 3.6)$ \\
\hline Hand baiting & 126 & $16(13.8 ; 3.3)$ & 130 & $27(20.6 ; 3.0)$ \\
\hline Total & 285 & $41(15.4 ; 2.4)$ & 298 & $63(21.3 ; 2.3)$ \\
\hline \multicolumn{5}{|l|}{ Combined } \\
\hline Helicopter & 291 & $43(15.0 ; 2.2)$ & 320 & $74(23.8 ; 2.3)$ \\
\hline Hand Baiting & 244 & $37(15.6 ; 2.7)$ & 259 & $65(24.5 ; 3.5)$ \\
\hline Total & 535 & $80(15.3 ; 1.7)$ & 579 & $139(24.2 ; 2.1)$ \\
\hline
\end{tabular}

${ }^{a}$ Seroprevalence (\%) is calculated by calculating the mean of the seroprevalence for each study cell and not the overall total positive/total captured.

In the southern study site, 2 raccoon home ranges were only approximately $50 \%$ baited because of a shift in raccoon movements relative to the study cell, likely resulting an underestimate of bait density for those 2 home ranges. In the northern site in 2014, data from remote-download GPS collars showed that 2 raccoons had moved out of the study cells in which they were captured. An unintended consequence was that these cells did not receive cluster baits during 2014, although they were baited operationally at 75 baits/ $\mathrm{km}^{2}$. Raccoons sampled in these cells during 2014 were included in serologic analysis. Seroprevalence increased by $8.9 \%$ overall following baiting, for an average post-ORV seroprevalence of $24.2 \%$. This is still well below the recommended threshold for population immunity but essentially consistent with historical annual mean seroconversion following oral rabies vaccination using RABORAL V-RG (Slate et al. 2014, 2009).

Hand baiting typically relies on roads or trails to access raccoon habitat to apply baits, which can be a limiting factor in reaching some home ranges. As a result, aerial broadcast of baits is likely to be more effective in reaching a higher proportion of raccoon home ranges than hand application in many areas, simply because of limited access to interior habitats by personnel during hand baiting. Bait application by helicopter using cluster baiting or individual baits may overcome this lack of access. In theory targeting core areas

Table 2. Model results for factors affecting the difference in seroprevalence in raccoons between pre- and post-oral rabies vaccination application, Chattanooga, Tennessee, USA, 2013-2014. Results are from a linear mixedeffects model. All models include a random effect of cell nested in the bait strategy (helicopter or hand baiting). We ranked models using Akaike's Information Criterion corrected for small sample size $\left(\mathrm{AIC}_{c}\right)$. Smaller $\mathrm{AIC}_{c}$ values have more support, and the model weight $\left(w_{i}\right)$ shows the relative model support.

\begin{tabular}{lccccc}
\hline Model & $\boldsymbol{K}^{\mathbf{a}}$ & $\mathbf{A I C}_{\boldsymbol{c}}$ & $\mathbf{\Delta A I C}_{\boldsymbol{c}}$ & $\boldsymbol{w}_{\boldsymbol{i}}$ & $\mathbf{L L}^{\mathbf{b}}$ \\
\hline Intercept only & 3 & -32.12 & 0.00 & 0.50 & 19.66 \\
Yr & 4 & -31.50 & 0.62 & 0.37 & 20.80 \\
Bait strategy & 4 & -29.26 & 2.86 & 0.12 & 19.68 \\
Yr $\times$ bait strategy & 6 & -24.81 & 7.30 & 0.01 & 20.88 \\
\hline
\end{tabular}

${ }^{a}$ Number of parameters in the model.

${ }^{\mathrm{b}}$ Log likelihood for the model. may be an effective strategy, but detailed knowledge of individual raccoon use of the landscape is typically unknown prior to initiating ORV operations. Although $50 \%$ of core areas were not reached during aerial application, it is likely related to flight-line spacing or to the lower frequency of cluster baiting. Reducing the flight-line spacing from $750 \mathrm{~m}$ to $500 \mathrm{~m}$ or lower could result in more consistent distribution of ORV baits to raccoons in some targeted suburban environments. Post hoc simulations of aerially applying baits with $500 \mathrm{~m}$ between transects but the same overall application rate $\left(75 / \mathrm{km}^{2}\right)$ suggest $15 / 18$ and $13 / 18$ core areas would be reached at clusters of $6(178 \mathrm{~m}$ between clusters) and 10 (266 m between clusters) baits, respectively. In this study we deposited clusters of 10 baits at $178-\mathrm{m}$ intervals along the flight line, rather than the operational standard of 1 bait every $18 \mathrm{~m}$, which may have contributed to relatively fewer baits applied aerially to core areas.

\section{MANAGEMENT IMPLICATIONS}

The applied nature and results of this research directly affected current ORV baiting strategies targeting raccoons by increasing the use of helicopters in areas where it was potentially more efficient, and at least as effective, as hand baiting. Helicopter cluster bait application and hand baiting by vehicle using Raboral V-RG have similar results in terms of seroconversion rates in raccoon populations and the degree to which the target species has access to bait based on estimated home range. In addition, depositing individual baits at regularly spaced intervals, rather than clusters, may increase the ability to target raccoon core areas and provide a more even distribution of ORV baits in suburban raccoon habitat. Evaluation of additional strategies are needed because both methods failed to achieve herd immunity necessary to disrupt rabies transmission in raccoons.

\section{ACKNOWLEDGMENTS}

Thanks to A. J. Davis for statistical assistance and A. T. Gilbert for a critical review of an early draft of this manuscript. Special thanks to K. W. Baker, A. R. Brown, M. A. Craig, S. A. Dowlen, J. D. Freye, W. A. Guigou, J. C. Hamby, B. D. Lane, J. M. Mathenia, C. E. Muir, B. D. 
Sunderland, and M. J. Wellman for exceptional field assistance and to K. M. Blanton for logistics and personnel assistance. Funding was provided by the USDA/Animal and Plant Health Inspection Service/Wildlife Services/National Rabies Management Program.

\section{LITERATURE CITED}

Bates, D., M. Maechler, B. Bolker, and S. Walker. 2015. Fitting linear mixed-effects models using lme4. Journal of Statistical Software 67:1-48.

Beasley, J. C., T. C. Atwood, M. E. Byrne, K. C. VerCauteren, S. R. Johnson, and O. E. Rhodes Jr. 2015. A behaviorally-explicit approach for delivering vaccine baits to mesopredators to control epizootics in fragmented landscapes. PLOS ONE 10(1):e0113206.

Benhamou, S. 2011. Dynamic approach to space and habitat use based on biased random bridges. PLoS ONE 6(1):e14592. doi: 10.1371/journal. pone.0014592.

Berentsen, A. R., R. S. Miller, R. Misiewicz, J. L. Malmberg, and M. R. Dunbar. 2014. Characteristics of white-tailed deer visits to cattle farms: implications for disease transmission at the wildlife-livestock interface. European Journal of Wildlife Research 60:161-170.

Blackwell, B. F., T. W. Seamans, R. J. White, Z. J. Patton, R. M. Bush, and J. D. Cepek. 2004. Exposure time of oral rabies vaccine baits relative to baiting density and raccoon population density. Journal of Wildlife Diseases 40:222-229.

Boulanger, J. R., L. L. Bigler, P. D. Curtis, D. H. Lein, and A. J. Lembo Jr. 2008. Comparison of suburban vaccine distribution strategies to control raccoon rabies. Journal of Wildlife Diseases 44:1014-1023.

Burnham, K. P., and D. R. Anderson. 2002. Model selection and multimodel inference: a practical information-theoretic approach. Springer-Verlag, New York, New York, USA.

Campbell, T. A., and D. B. Long. 2007. Species-specific visitation and removal of baits for delivery of pharmaceuticals to feral swine. Journal of Wildlife Diseases 43:485-491.

Cornélis, D., S. Benhamou, G. Janeau, N. Morellet, M. Ouedraogo, and M. N. de Visscher. 2011. Spatiotemporal dynamics of forage and water resources shape space use of West African savanna buffaloes. Journal of Mammalogy 92:1287-1297.

Krebs, J. W., E. J. Mandel, D. L. Swerdlow, and C. E. Rupprecht. 2005. Rabies surveillance in the United States during 2004. Journal of the American Veterinary Medical Association 227:1912-1925.

Kreeger, T. J., and J. M. Arnemo. 2007. Handbook of wildlife chemical immobilization. Sunquest Publishing, Laramie, Wyoming, USA.

Nugent, G., B. Warburton, C. Thomson, M. L. Cross, and M. C. Coleman. 2012. Bait aggregation to reduce cost and toxin use in aerial 1080 baiting of small mammal pests. Pest Management Science 68:1374-1379.

Olson, C. A., K. D. Mitchell, and P. A. Werner. 2000. Bait ingestion by free-ranging raccoons and nontarget species in an oral rabies vaccine field trial in Florida. Journal of Wildlife Diseases 36:734-743.

Rees, E. E., B. A. Pond, R. R. Tinline, and D. Belanger. 2013. Modelling the effect of landscape heterogeneity on the efficacy of vaccination for wildlife infectious disease control. Journal of Applied Ecology 50:881-891.
Reynolds, J. J. H., B. T. Hirsch, S. D. Gehrt, and M. E. Craft. 2015. Raccoon contact networks predict seasonal susceptibility to rabies outbreaks and limitations of vaccination. Journal of Animal Ecology 84:1720-1731.

Robbins, A. H., M. D. Borden, B. S. Windmiller, M. Niezgoda, L. C. Marcus, S. M. O’Brien, S. M. Kreindel, M. W. McGuill, A. DeMaria Jr., C. E. Rupprecht, and S. Rowell. 1998. Prevention of the spread of rabies to wildlife by oral vaccination of raccoons in Massachusetts. Journal of the American Veterinary Medical Association 213:1407-1412.

Rosatte, R. C., D. Donovan, M. Allan, L. Bruce, T. Buchanan, K. Sobey, B. Stevenson, M. Gibson, T. MacDonald, M. Whalen, J. C. Davies, F. Muldoon, and A. Wandeler. 2009. The control of raccoon rabies in Ontario Canada: proactive and reactive tactics, 1994-2007. Journal of Wildlife Diseases 45:772-784.

Rupprecht, C. E., and J. S. Smith. 1994. Raccoon rabies: the re-emergence of an epizootic in a densely populated area. Seminars in Virology 5:155-164.

Sattler, A. C., R. A. Krogwold, T. E. Wittum, C. E. Rupprecht, T. P. Algeo, D. Slate, K. A. Smith, R. L. Hale, G. A. Nohrenberg, C. D. Lovell, M. Niezgoda, A. J. Montoney, and R. D. Slemons. 2009. Influence of oral rabies vaccine bait density on rabies seroprevalence in wild raccoons. Vaccine 27:7187-7193.

Slate, D., T. P. Algeo, K. M. Nelson, R. B. Chipman, D. Donovan, J. D. Blanton, M. Niezgoda, and C. E. Rupprecht. 2009. Oral rabies vaccination in North America: opportunities, complexities and challenges. PLOS Neglected Tropical Diseases 3(12):e549.

Slate, D., R. B. Chipman, T. P. Algeo, S. A. Mills, K. M. Nelson, C. K. Croson, E. J. Dubovi, K. VerCauteren, R. W. Renshaw, T. Atwood, S. Johnson, and C. E. Rupprecht. 2014. Safety and immunogenicity of Ontario rabies vaccine bait (ONRAB) in the first US field trial in raccoons (Procyon lotor). Journal of Wildlife Diseases 50:582-595.

Slate, D., C. E. Rupprecht, J. A. Rooney, D. Donovan, D. H. Lein, and R. B. Chipman. 2005. Status of oral rabies vaccination in wild carnivores in the United States. Virus Research 111:68-75.

Smith, J. S., P. A. Yager, and G. M. Baer. 1996. A rapid fluorescent focus inhibition test (RFFIT) for determining rabies virus-neutralizing antibody. Pages 181-190 in F. X. Meslin, M. M. Kaplan, and H. Koprowski, editors. Laboratory techniques in rabies, fourth edition. World Health Organization, Geneva, Switzerland.

Thulke, H.-H., and D. Eisinger. 2008. The strength of 70\%: revision of a standard threshold of rabies control. Developments in Biologicals 131:291-298.

United States Department of Agriculture NRCS National Geospatial Center of Excellence. 2011. National Land Cover Dataset. https://gdg.sc. egov.usda.gov/GDGHome.aspx. Accessed 30 Nov 2016.

Wehtje, M., and M. E. Gompper. 2011. Effects of an experimentally clumped food resource on raccoon Procyon lotor home-range use. Wildlife Biology 17:25-32.

Zuur, A., E. N. Leno, N. Walker, A. A. Saveliev, and G. M. Smith. 2009. Mixed effects models and extensions in ecology with R. Springer-Verlag, New York, New York, USA.

Associate Editor: Robin Russell. 